\title{
Accuracy of in-line milk composition analysis with diffuse reflectance near-infrared spectroscopy
}

\author{
A. Melfsen, ${ }^{1}$ E. Hartung, and A. Haeussermann \\ Christian-Albrechts-University Kiel, Institute of Agricultural Engineering, 24098 Kiel, Germany
}

\begin{abstract}
Knowledge of daily milk composition changes can assist in monitoring dairy cow health and can help to detect nutritional imbalances. An analytical tool offering the possibility of analyzing milk during the daily milking routine would provide such information. Near-infrared (NIR) spectroscopy can analyze multiple constituents in a given substrate at the same time. In this study, a special NIR in-line milk-analyzing device was designed, and its ability to predict the contents of fat, protein, lactose, and urea and the somatic cell count in milk during the milking process was evaluated. The NIR spectra were acquired with a diode array spectrometer in diffuse reflection in the wavelength range 851 to $1649 \mathrm{~nm}$. The spectra originated from a total of 785 partial milkings out of 84 composite milkings. Corresponding subsamples of the composite milkings were used for reference analysis $(\mathrm{n}=785)$. Excellent validation results were obtained with regard to the coefficients of determination $\left(\mathrm{R}^{2}=0.99,0.98\right.$, and 0.92), and standard errors of prediction $(0.09,0.05$, and 0.06$)$ for fat (\%), protein (\%), and lactose (\%), respectively. Satisfying results were achieved for urea content $(\mathrm{mg} / \mathrm{L})$ and logarithmically transformed SCC in milk, with $\mathrm{R}^{2}$ of 0.82 and 0.85 and standard errors of prediction of 19.3 and 0.18 , respectively. The accuracy of predicting protein, lactose, and urea contents was in accordance with international recommendations for reproducibility specified for in-line analytical devices.

Key words: in-line milk analysis, reproducibility, diffuse reflectance near-infrared spectroscopy, somatic cell count classification
\end{abstract}

\section{INTRODUCTION}

Monitoring animal health and metabolic functions is increasingly part of herd management in dairy production. Changes in milk composition provide valuable information for detecting abnormalities in health and

Received January 27, 2012.

Accepted July 18, 2012.

${ }^{1}$ Corresponding author: amelfsen@ilv.uni-kiel.de nutrition. In general, the concentrations of fat, protein, lactose, and urea and the SCC in milk are collected once or twice a month in national DHI programs. These records are basically used for estimation of breeding values. The time delay between sampling and feedback reduces their benefit as a management tool. A more frequent recording of individual milk constituents during the milking process would provide significant benefits for improved herd management (SvennerstenSjaunja et al., 1997). Fat concentration in milk is influenced by, for example, the physical structure of and crude fiber in the ration. Knowledge of the protein and urea contents in milk allows conclusions to be drawn regarding the balance of energy supply and protein concentration in the diet. Some studies suggest measuring the milk composition of individual cows (e.g., milk FA composition, milk fat, milk protein), and the milk composition ratios based thereon, to indicate energy balance and metabolic imbalances (Heuer et al., 1999, 2001a; Friggens et al., 2007; McParland et al., 2011; Toni et al., 2011). Cows with a fat-to-protein ratio above 1.5 (on the first test day) had higher risks of ketosis, for example, in the investigations by Heuer et al. (1999). Heuer et al. (2001a) tested for estimations of acetone in milk by using Fourier transform infrared spectroscopy. Predictions of subclinical ketosis based thereon resulted in 95 to $100 \%$ sensitivity and 96 to $100 \%$ specificity, depending on the threshold used for subclinical ketosis (Heuer et al., 2001a).

Friggens et al. (2007) reported promising results in predicting the average energy balance of cows based on frequent measurements of milk yield, milk fat, and milk protein at each milking. The authors asserted the benefits of frequent measurements and the importance of focusing on individual cows rather than cow groups if predicted indicators are used for nutritional diagnostics (Friggens et al., 2007). Likewise, Maltz et al. (2009) underlined the importance of an in-line daily milk composition sensor for efficient feeding of dairy cows during the transition time when they compared the allocation of concentrates using either daily milk composition data or records of periodical milk tests.

Somatic cell count and, for example, concentrations of minerals and lactose in raw milk are common indica- 
tors of udder diseases (Bruckmaier et al., 2004), and they can be a helpful tool in monitoring udder health. Somatic cell count in milk from healthy quarters is, in general, below 100,000 cells/mL (DVG, 1994; NMC, 2001). The probability of a mastitic quarter increases with increasing SCC. Published by the IDF in 1967 (IDF, 1967), a value of 500,000 cells $/ \mathrm{mL}$, in combination with pathogen findings, is used to define IMI (Hillerton, 1999). To date, a threshold of, respectively, 200,000 cells/mL (NMC, 2001) and 100,000 cells/mL (DVG, 2002) in quarter milk samples is suggested by associations in the United States and in Germany as a clear indication of an inflammatory response and likely IMI. Because IMI are defined by SCC and the presence of pathogens (IDF, 1987; DVG, 2002), the SCC itself can basically be only an indicator. Several operational SCC thresholds are in use under field conditions and vary according to the target and milk origin (quarter, composite, or bulk milk; Detilleux et al., 1999; Schukken et al., 2003).

The robustness of near-infrared (NIR) equipment and the possibility of rapidly identifying multiple constituents at the same time makes NIR spectroscopy (NIRS) a useful tool for analyzing milk during the milking process with a high temporal frequency in an in-line application in milking parlors. However, lightscattering effects make it difficult to create an adequate sample presentation for NIR analysis. Raw milk as an oil-in-water emulsion is a turbid opaque medium with multiple light-scattering effects caused by $\mathrm{CN}$ micelles and fat globules of different sizes (Jääskeläinen et al., 2001). Typical bovine milk contains more than $10^{10}$ milk fat globules/mL, with diameters ranging from $<0.2$ to $>15 \mu \mathrm{m}$ and $\mathrm{CN}$ micelles with diameters ranging from $<0.01$ to $>0.6 \mu \mathrm{m}$ (Töpel, 2004; Huppertz et al., 2006).

Analyzing raw milk by NIRS has been a research topic in several studies in recent years (Tsenkova et al., 1999, 2001a,b, 2006; Schmilovitch et al., 2000; Chen et al., 2002; Kawasaki et al., 2008; Saranwong and Kawano, 2008; Aernouts et al., 2011). A preliminary static measurement setup, described in Melfsen et al. (2012), showed good accuracy in predicting fat, protein, and lactose contents in milk. Hence, the results in the literature of the last decade suggest that NIRS is a promising tool to predict concentrations of some milk constituents. Nevertheless, studies with an in-line measurement setup, large databases, and independent validation of the accuracy of in-line applications of milk analysis are still missing in the literature.

In the current study, a device for NIR measurements in diffuse reflectance mode, in-line in a milking parlor, was designed and evaluated. Measurements were done in a wavelength region of 851 to $1,649 \mathrm{~nm}$ with a diode array spectrometer. The aim of this study was to evalu- ate the accuracy of the measuring device for predicting concentrations of fat, protein, lactose, and urea as well as the SCC in milk from different cows during the milking process. Spectra were taken continuously during the milking process with the aim of predicting milk contents in subsamples of complete milkings.

\section{MATERIALS AND METHODS}

\section{Measuring Setup}

The experimental measuring setup consisted of a commercially available milk meter (LactoCorder, WMB AG, Balgach, Switzerland), a specially designed measuring cell designed as a flow-through chamber, a sample bottle, a contact reflection sensor head (PSS-HB01), and a diode array spectrometer system with an InGaAs detector (PSS-1720; both from Polytec GmbH, Waldbronn, Germany).

The measuring cell was attached to the sampling valve of the milk meter. The valve diverted a representative sample of $6.25 \%$ of the raw milk during the milking process to the NIR measuring cell. Raw milk from the bypass system was collected in a sample bottle after passing the measuring cell for reference analysis of selected milk constituents. The contact reflection NIR sensor head was attached to the measuring cell and connected to the spectrometer. The setup was inserted in the long milk tube at 1 milking place in a side-byside milking parlor at the education and research farm of the Chamber of Agriculture, Schleswig-Holstein, in Futterkamp, Germany.

\section{NIR Spectra Acquisition}

Near-infrared spectra were acquired in diffuse reflection in the wavelength region of 851 to $1,649 \mathrm{~nm}$. Spectra were taken during the entire milking process every $500 \mathrm{~ms}$. The layer thickness of the raw milk flow in the measuring cell was $30 \mathrm{~mm}$. Dark current and white reference spectra were acquired before each cow was milked. After every $2 \mathrm{~kg}$ of milking, the spectra were averaged, and bypassed milk was sampled for reference analysis. This led to a total of 785 raw milk spectra.

\section{Milk Sampling}

Measurements were done during 3 measuring sequences, each consisting of 4 consecutive milkings (2 morning and 2 evening milkings). Between the beginning and end of the first and the third measuring sequence was a time period of 3 mo. The 3 measuring sequences led to a total of 84 cow milkings from 43 different cows, which were all used for spectra acquisition 
Table 1. Statistical performance of calibration and validation ${ }^{1}$

\begin{tabular}{|c|c|c|c|c|c|c|}
\hline \multirow[b]{2}{*}{ Item } & \multicolumn{2}{|c|}{ Calibration $(\mathrm{n}=523)$} & \multicolumn{4}{|c|}{ Validation $(\mathrm{n}=262)$} \\
\hline & SEC & $\mathrm{R}_{\text {cal }}^{2}$ & SEP & $\mathrm{R}_{\text {val }}^{2}$ & Bias & $\mathrm{RPD}$ \\
\hline Fat $(\%)$ & 0.09 & 0.998 & 0.09 & 0.998 & -0.0004 & 21.72 \\
\hline Protein $(\%)$ & 0.04 & 0.99 & 0.05 & 0.98 & 0.0003 & 6.44 \\
\hline Lactose (\%) & 0.05 & 0.96 & 0.06 & 0.92 & -0.0076 & 3.51 \\
\hline Urea $(\mathrm{mg} / \mathrm{L})$ & 15.24 & 0.89 & 19.32 & 0.82 & -1.6959 & 2.36 \\
\hline Log SCC & 0.15 & 0.90 & 0.18 & 0.85 & -0.0119 & 2.57 \\
\hline
\end{tabular}

${ }^{1} \mathrm{SEC}=$ standard error of calibration; $\mathrm{R}^{2}$ cal $=$ coefficient of determination of calibration; $\mathrm{SEP}=$ standard error of prediction; $\mathrm{R}_{\text {val }}^{2}=$ coefficient of determination of validation; $\mathrm{RPD}=$ ratio of standard deviation of the validation set to SEP.

and milk sampling. Because cows appeared randomly at the milking place where the measuring setup was installed, some cows appeared more than once in the data set. The cows were in their first to fifth lactation $(12,8,12,7$, and 4 cows in the first, second, third, fourth, and fifth lactation, respectively) and 7 to 312 DIM $(16,15$, and 12 cows at 1 to 100,101 to 200 , and $>200$ DIM, respectively). Bypassed milk was sampled for reference analysis after every $2 \mathrm{~kg}$ of milking, which led to 785 subsamples of total milkings (on average, 9.3 samples per cow milking). An aliquot of $45 \mathrm{~mL}$ per milk sample was conserved with bronopol after sampling. All samples were sent to the laboratory for reference analysis of fat, protein, lactose, and urea concentrations and SCC (MilkoScan FT+ and Fossomatic FC, respectively; Foss-Electric A/S, Hillerød, Denmark). The SCC values were logarithmically transformed (log SCC) to obtain normally distributed data.

\section{Preprocessing of Spectra, Calibration, and Validation}

Chemometric tools (SL Calibration Wizard v.1.1.0; SensoLogic GmbH, Norderstedt, Germany) were used for preprocessing of spectra, calibration of different milk constituents, and validation of results. Spectra of milking parts were merged into 1 data set $(\mathrm{n}=785)$. Of this data set, NIR spectra were divided into 2 random sample sets: a calibration set containing two-thirds of all samples $(\mathrm{n}=523)$ and a test set containing the remaining samples $(\mathrm{n}=262)$. The test set was used for validation. Random selection was done by sorting the samples according to the concentration of the respective milk content and assigning every third of the sorted samples to the test set. Spectra normalization was applied to NIR reflectance spectra to reduce scattering effects. The applied normalization of spectra scaled the measured reflection to an ordinate between 0 and 1 , where the minimum and maximum reflection value of each spectrum corresponded to none (i.e., 0) and total (i.e., 1) reflection, respectively, in the normalized spectra.
The statistical partial least squares method (PLS-1) was applied to each calibration and milk constituent. Cross-validation (20 cross-validation segments) was used to estimate the number of principal components for the calibration. Validation was based on the previously created test set. Validation criteria for each partial least squares model were the coefficient of determination $\left(\mathrm{R}^{2}\right)$, the standard error of prediction $(\mathbf{S E P})$, and the ratio of prediction to deviation (RPD), defined as the ratio of the standard deviation of the validation set to the SEP (Williams, 2001; Table 1).

Residuals (RES) of NIR estimates per sample per milk constituent were calculated as the deviation of the predicted content $\left(y_{\text {pred }}\right)$ from the laboratory content $\left(y_{a c t}\right)$ :

$$
\mathrm{RES}=y_{\text {pred }}-y_{\text {act }}
$$

\section{Evaluation of Prediction Accuracy with Regard to Precision Recommendations}

One parameter defining the precision of the reference analysis is the reproducibility $(\boldsymbol{R})$. When different DHI laboratories participate in an interlaboratory test, threshold values for $R$ are recommended (routine analytical methods with midinfrared instruments) by the International Dairy Federation [IDF; standard IDF 141C:2000 (IDF 2000)], the International Organization for Standardization [ISO; standard 9622 (ISO, 1999)], and the Arbeitsgemeinschaft Deutscher Rinderzüchter e.V. [ADR; recommendation 1:13 (ADR, 2002)]. To calculate $R$ in the interlaboratory test, 1 milk sample is sent to several participating laboratories. The standard deviation $\left(\boldsymbol{S} \boldsymbol{D}_{L}\right)$ is calculated based on analytical results of the participating laboratories, whereby $R$ is defined by a multiple of $S D_{L}$ with

$$
R=2.8 \times S D_{L} .
$$

The Guidelines of the International Committee for Animal Recording (ICAR) for on-farm milk analy- 
Table 2. Reproducibility $(R)$ limits for milk analysis (laboratory, at-line, and in-line recommendations), ${ }^{1}$ and percentage of NIR prediction residuals (RES) equal to or below $R\left(\mathrm{RES}_{\leq \mathrm{R}}, \%\right)$

\begin{tabular}{|c|c|c|c|c|c|c|c|c|c|}
\hline Item & \multicolumn{2}{|c|}{ Laboratory IDF/ISO } & \multicolumn{2}{|c|}{ Laboratory ICAR/ADR } & \multicolumn{2}{|c|}{ At-line } & \multicolumn{2}{|c|}{ In-line } & $2 \times \mathrm{SEP}^{2}$ \\
\hline Fat $(\%)$ & $0.13^{*}$ & 92.75 & $0.07^{\ddagger}$ & 73.28 & $0.14^{\ddagger}$ & 93.89 & $0.17^{\ddagger}$ & 95.80 & 0.17 \\
\hline Lactose $(\%)$ & - & - & $0.07^{\ddagger}$ & 80.92 & $0.14^{\ddagger}$ & 95.04 & $0.17^{\ddagger}$ & 98.47 & 0.13 \\
\hline Urea (mg/L) & - & - & $25.00^{+}$ & 84.35 & $50.00^{\circ}$ & 97.33 & $62.50^{\circ}$ & 100.00 & 38.64 \\
\hline
\end{tabular}

${ }^{1}$ Symbols indicate the reference(s) corresponding to the value of $R$ : an asterisk $(*)$ indicates adapted according to IDF standard 141C:2000 (IDF, 2000) and ISO standard 9622 (ISO, 1999; SD of fat: $0.045 \%$; SD of protein: $0.035 \%$ ); a plus sign (+) indicates ADR recommendation 1:13 (ADR, 2002); a dagger $(\ddagger)$ indicates the ICAR standard (ICAR, 2010); a bullet $(\bullet)$ indicates adapted according to the ICAR (2010) and ADR (2002) recommendations.

${ }^{2}$ The $2 \times$ SEP is the $95 \%$ confidence interval of the NIR prediction twice the standard error of the NIR prediction.

sis (ICAR, 2010) include specific precision limits for laboratory, at-line, and in-line milk analyzing devices. Usually, analysis of milk constituents with at-line and in-line milk analyzers is done more frequently than with laboratory instruments; consequently, lower performance and accuracy are acceptable. The tolerance is based on the possibility of averaging the analyzed results as long as no bias or only slight bias exists. The recommendations for $R$ for laboratory, at-line, and inline milk analyzers are presented in Table 2.

According to ISO standard 5725-1 (ISO, 1994), the maximum absolute difference between 2 single test results of the same sample in an interlaboratory test is required to be equal to or lower than $R$ with a $95 \%$ probability. The accuracy of the NIR calibration in the current study is comparable with the reproducibility between 2 laboratories if the maximum difference from the reference analysis is, with a $95 \%$ probability, at least equal to or below $R$. The validity of this comparison is, of course, limited to the evaluated data set and based on the assumption that the reference laboratory is not biased in comparison with other accredited laboratories. A $95 \%$ probability for the maximum difference between the predicted $y_{\text {pred }}$ and reference value $y_{a c t}$ was calculated by multiplying SEP by $2(2 \times$ SEP, 95\% confidence interval). Premises for calculating the $95 \%$ probability in this way are normally distributed RES and no significant bias, which were both fulfilled. Next to the comparison of $2 \times \mathrm{SEP}$ with $R$, calculations of the percentage of RES that are smaller than $R$ $\left(\mathbf{R E S}_{\leq \mathbf{R}}\right)$ were done for all milk contents (fat, protein, lactose, and urea) and different recommendations of $R$.

\section{Evaluation of the SCC Prediction}

To approve the prediction accuracy of SCC in comparison with other indirect methods, such as measurements of milk viscosity (e.g., California Mastitis Test; Schalm and Noorlander, 1957), the SCC values predicted with the NIR method were categorized and compared with SCC values from the laboratory. The categorization scheme adapted from Kamphuis et al. (2008) was used, with 6 different levels of SCC counts $(\leq 50,50 \leq$ $100,100 \leq 200,200 \leq 500,500 \leq 1,000,>1,000 \times 10^{3}$ cells $/ \mathrm{mL}$ ). A frequency table based on the 6 levels was created to categorize milk samples determined by the NIR-predicted and laboratory-analyzed SCC values.

Binary classifications of single SCC thresholds $(100,000,200,000$, and 500,000 cells/mL) were evaluated with the help of sensitivity and specificity. The sensitivity is the percentage of milk samples with high SCC values that were classified correctly,

$$
\begin{aligned}
& \text { [true positives } /(\text { true positives } \\
& \quad+\text { false negative })] \times 100,
\end{aligned}
$$

whereas the specificity is the percentage of milk samples with low SCC values that were classified correctly,

$$
\begin{aligned}
& \text { [true negative } /(\text { false positive } \\
& + \text { true negative })] \times 100 .
\end{aligned}
$$

\section{RESULTS}

The total range, mean, and standard deviation of contents of fat ( 0.7 to $12.3 \%, \bar{x}=3.6 \pm 1.87 \%)$, protein (2.4 to $4.0 \%, \bar{x}=3.1 \pm 0.3 \%$ ), lactose (3.9 to $5.2 \%, \bar{x}$ $=4.7 \pm 0.22 \%$ ), and urea (121 to $380 \mathrm{mg} / \mathrm{L}, \bar{x}=258$ $\pm 45.5 \mathrm{mg} / \mathrm{L}$ ), and the $\log \mathrm{SCC}$ (3.5 to $6.0, \bar{x}=4.5 \pm$ 0.46 ) in the milk samples (reference analysis) covered almost the same range in the calibration and validation sets. Because milk samples of every $2 \mathrm{~kg}$ of milk were taken, a large range in the single milk contents was covered. In particular, fat content varied considerably, with a range of values from 0.7 to $12.3 \%$. The data for all milk constituents investigated were normally distributed. 
Figure 1a illustrates typical NIR reflectance spectra of raw milk during 1 milking. From the beginning to the end of the milking, the reflectance intensity increased continuously over the entire wavelength range. This shift in the spectra was only partly explained by variations in the chemical composition of the milk during the milking process. With a high probability, the majority of this shifting was due to scattering effects caused by variations in the particle size and milk:air mixtures.

The total 785 NIR reflectance spectra of raw milk are shown in Figure 1b. The spectra showed characteristic absorption peaks at 970 and $1,450 \mathrm{~nm}$ related to the first and second overtone bond vibrations of $\mathrm{O}-\mathrm{H}$. Additional absorption bands of numerous different second overtone $\mathrm{C}-\mathrm{H}$ bonds are shown around 1,195 $\mathrm{nm}$. Other absorption bands related to relevant functional groups of the protein, lactose, and urea contents in milk were rather weak compared with the absorption bands of the $\mathrm{O}-\mathrm{H}$ and $\mathrm{C}-\mathrm{H}$ bonds. These absorption bands are hardly recognizable without statistical methods. Hence, chemometric tools are crucial to calibrate the prediction models for the individual milk constituents. The spectral region was sufficient to expose the third and second overtone absorption bands of the relevant chemical bonds and was capable of high light penetration in water-based fluids. The variation in reflectance intensity was high over the entire wavelength range. Normalization preprocessing was done to reduce scattering effects and related shifting effects. The effects of normalization preprocessing on the raw milk spectra are shown in Figure 1c. The statistical performance of the model developed (calibration) and the accuracy of prediction of the milk components fat, protein, lactose, and urea and the $\log$ SCC (validation) are shown in Table 1.

With respect to the coefficient of determination of the validation test set $\left(\mathbf{R}^{2}\right.$ val $)$, more than 99, 98, and $92 \%$ of the variation in the ingredients fat, protein, and lactose could be explained by the NIR spectra measuring device and chemometric analysis as applied in this study. For urea content and $\log \mathrm{SCC}, \mathrm{R}_{\text {val }}^{2}$ reached values of 0.82 and 0.85 , respectively. The relationship between actual contents from the laboratory analysis and the NIR-predicted contents for all 5 milk constituents for the independent validation samples can be seen in the scatter plots in Figure 2.

The bias was rather small for all milk constituents, considering the range of values. The SEP for fat, protein, and lactose $(\mathrm{SEP}=0.09,0.05$, and $0.06 \%$, respectively) were rather small compared with the range of values and with their standard deviations. This was also expressed by an excellent RPD of 21.7 for fat, a very good RPD of 6.4 for protein, and a good RPD for

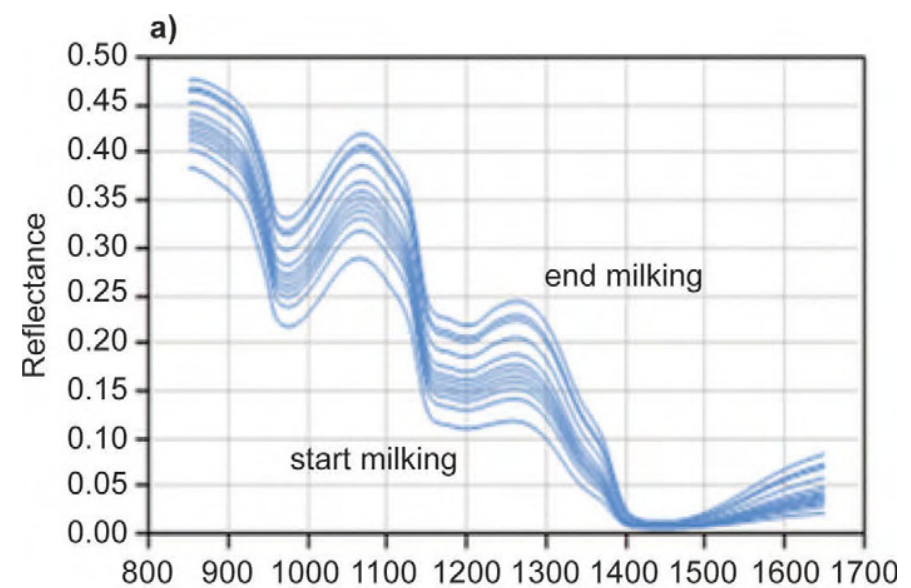

b)

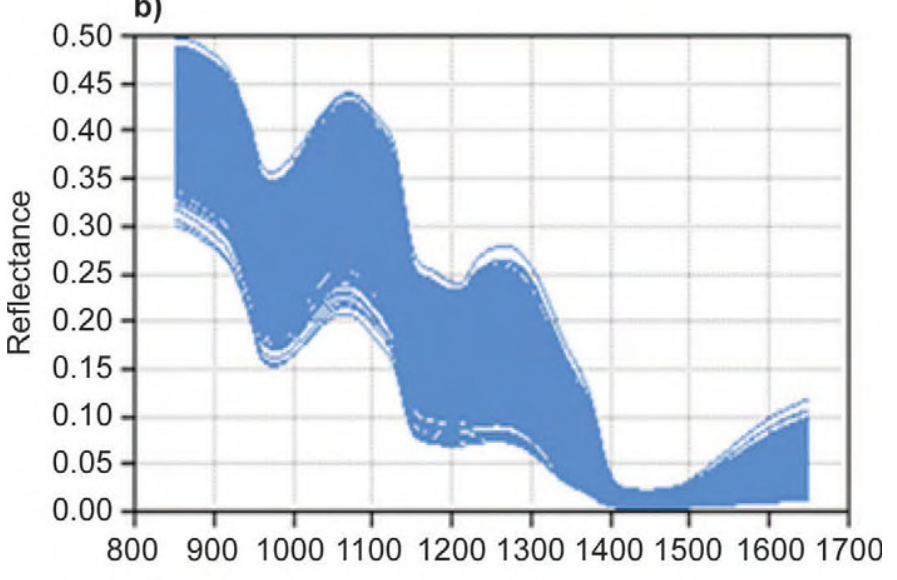

c)

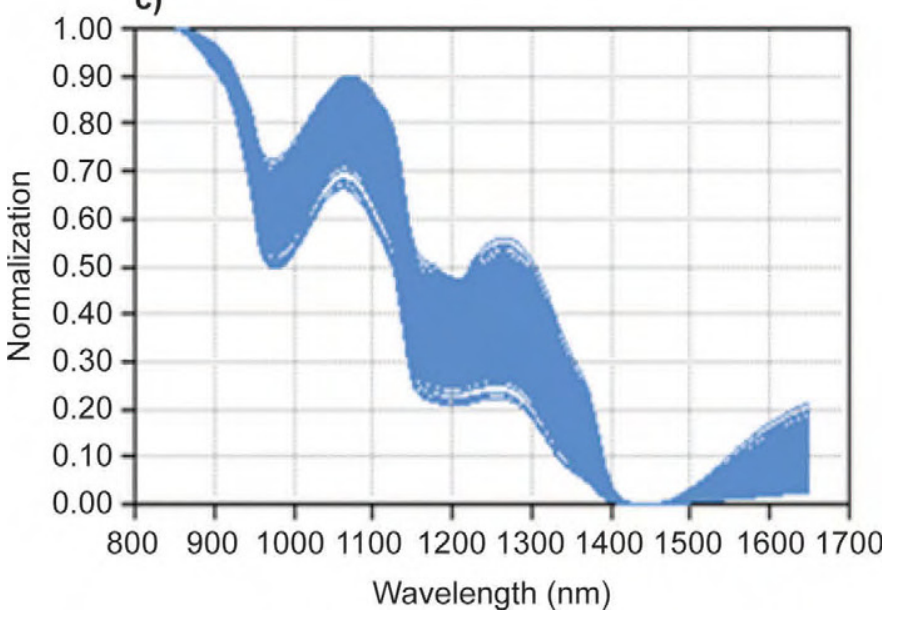

Figure 1. Near-infrared (NIR) spectra (851 to 1,649 nm) of raw milk from an in-line measurement setup in diffuse reflectance mode. (a) Typical spectra of milk during 1 cow milking $(\mathrm{n}=12)$; (b) spectra of all raw milk samples $(\mathrm{n}=785)$; (c) normalized NIR reflectance spectra of all raw milk samples $(\mathrm{n}=785)$. Color version available in the online PDF.

lactose content (Table 1). The SEP of urea content and the $\log$ SCC were rather small as well, but because of a small standard deviation also in the validation set, 

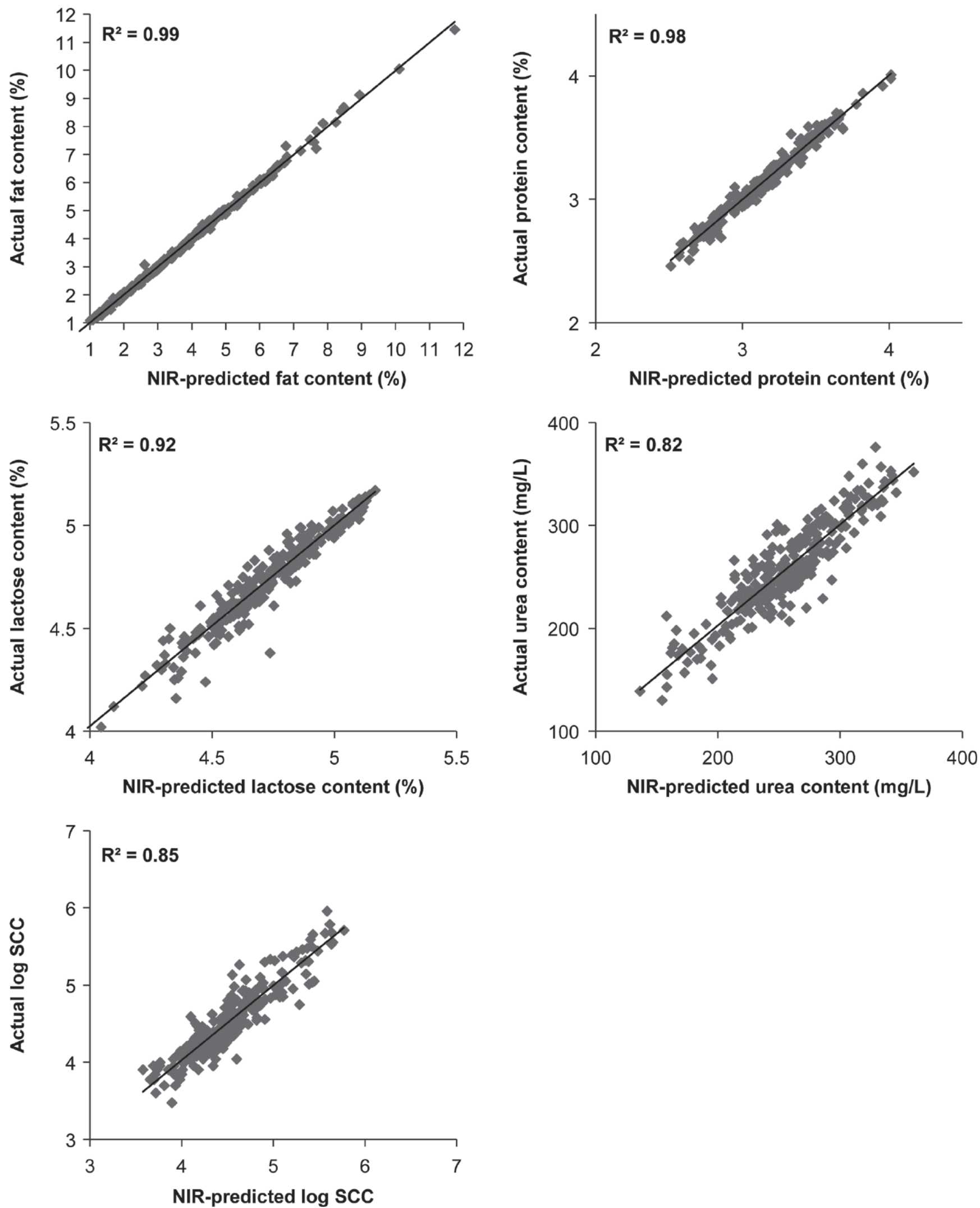

Figure 2. Relationship of actual and near-infrared (NIR)-predicted values of the milk constituents fat (\%), protein (\%), lactose (\%), and urea $(\mathrm{mg} / \mathrm{L})$ and the $\log$ SCC for the independent validation samples $(\mathrm{n}=262)$. 
Table 3. Number of samples in SCC classes as predicted by the near-infrared (NIR) method (SCC NIR) or determined by laboratory analysis (SCC LAB)

\begin{tabular}{|c|c|c|c|c|c|c|c|}
\hline \multirow{2}{*}{$\begin{array}{l}\text { SCC NIR } \\
\left(\times 10^{3} \text { cells } / \mathrm{mL}\right)\end{array}$} & \multicolumn{6}{|c|}{$\mathrm{SCC}$ LAB $\left(\times 10^{3}\right.$ cells $\left./ \mathrm{mL}\right)$} & \multirow[b]{2}{*}{ Total } \\
\hline & $\leq 50$ & 50 to $\leq 100$ & 100 to $\leq 200$ & 200 to $\leq 500$ & 500 to $\leq 1,000$ & $>1,000$ & \\
\hline 50 to $\leq 100$ & 7 & 22 & 5 & 1 & 0 & 0 & 35 \\
\hline 100 to $\leq 200$ & 0 & 9 & 2 & 5 & 0 & 0 & 16 \\
\hline 200 to $\leq 500$ & 0 & 0 & 5 & 12 & 2 & 0 & 19 \\
\hline 500 to $\leq 1,000$ & 0 & 0 & 0 & 0 & 1 & 0 & 1 \\
\hline
\end{tabular}

smaller RPD values of 2.4 and 2.6 for urea and $\log$ SCC, respectively, were achieved (Table 1$)$.

The values of $2 \times$ SEP for the 4 tested milk constituents are listed in Table 2. Ideally, $2 \times$ SEP should be less than or in a range similar to the values for $R$ shown in Table 2 . The more $2 \times$ SEP exceeds $R$, the less the milk sample RES lies inside the range of the recommendations for $R$. The $\mathrm{RES}_{\leq \mathrm{R}}$ represents the percentage of milk sample RES inside this range. The RES $\leq R$ calculated for measurement requirements in laboratory, at-line, and in-line conditions are shown in Table 2.

The lowest correspondence between $2 \times$ SEP and the recommendations for $R$ according to ICAR and ADR (0.07; Table 2) was achieved for the estimation of fat content in milk. In $73 \%$ of the cases, the accuracy of the predicted value was within the recommended range of ICAR (2010) and ADR (2002) laboratory requirements, but in $93 \%$ of the cases, it was within the recommended range of IDF and ISO standards. These results diverge from the excellent RPD value for the predicted fat content in milk. With the focus on comparing $2 \times$ SEP with the recommendations for $R$, much more sufficient accuracy was achieved for milk protein, lactose, and urea contents. As a result for these milk contents, 88,81 , and $85 \%$ of the protein, lactose, and urea RES, respectively, were within the laboratory recommendations from ICAR (2010) and ADR (2002). The RES for protein prediction compared with reproducibility recommendations from IDF standard 141C:2000 (IDF, 2000) and ISO standard 9622 (ISO, 1999) led to RES $\leq \mathrm{R}$ of more than $95 \%$, which consequently describes a sufficient method of analysis. Much higher percentages, up to $100 \%$, were achieved when RES of all 4 milk contents were compared with at-line and in-line recommendations.

Recalculated SCC from the predicted log SCC and their relationship to actual SCC from the reference analysis are shown in Table 3 , categorized into 6 different SCC classes. In total, 207 out of 262 milk samples $(79 \%)$ were classified into the correct category when SCC was predicted with NIR technology. Milk samples with an SCC above 100,000 cells $/ \mathrm{mL}$ of milk were classified correctly, with a sensitivity of $77 \%$ and a specificity of $96 \%$. Considering classification according to an SCC threshold of 200,000 cells/mL, useful under field conditions (Schukken et al., 2003), a sensitivity of $71 \%$ and a specificity of $98 \%$ were achieved. With a threshold for SCC of 500,000 cells/mL, a sensitivity of $33 \%$ and a specificity of $100 \%$ were obtained.

\section{DISCUSSION}

The specially designed in-line milk analyzing setup and its connection to the teat cup cluster and the milk line offered an excellent possibility of acquiring spectra in the milk flow and collecting concomitant subsamples of total milkings. In this study, influences on the calibration from different cow feedings or from different milking parlors were kept at a minimum to examine the potential of NIR analysis. Parallel investigations showed that milk temperature in the measuring cell ranged between 34.1 and $39.3^{\circ} \mathrm{C}$ (maximum measurement error: $0.3^{\circ} \mathrm{C}$ ) and had a negligible influence on the model results.

Standardized criteria for validation are important to ensure reliable conclusions regarding the performance of a tested measuring device. Williams (2001) classified the performance of NIR calibrations for agricultural products by RPD, provided that input values are equally distributed. In this respect, RPD values above 8.0 indicate excellent calibrations. Ratios of prediction to deviation values above 3.0 are suitable for analytical purposes in most NIR applications in agricultural products with low standard deviations. Lower RPD values are useful for very rough screening or are declared as not recommended (Williams, 2001). Despite the normally distributed milk constituents in this study, excellent and very good calibration results were achieved only for milk fat and protein. The lactose prediction results are useful for analytical purposes with regard to the RPD value. The fat content in milk dominates the NIR spectra in the chosen range of 851 to 1,649 
$\mathrm{nm}$, next to the $\mathrm{O}-\mathrm{H}$ absorption bands. Strong second and third overtone absorption bands of $\mathrm{C}-\mathrm{H}$ and scattering effects from fat globules of different sizes in raw milk are characteristic. Small concentrations and overlapping $\mathrm{O}-\mathrm{H}$ absorption bands make it difficult to detect urea content in milk precisely. Nevertheless, the calibration of urea content in milk in the current study resulted in a small SEP and in a satisfying RPD value. Determining the SCC in raw milk with NIRS is rather difficult because this parameter is not defined through explicit chemical bonds. Because different milk constituent concentrations change along with high SCC in milk (Harmon, 1994), calibrations of SCC in NIR apply partly to these milk composition changes and partly to scattering effects attributable to somatic cells (Tsenkova et al., 2001a, 2009).

\section{Comparison with the Reference Method}

The accuracy of NIR analysis is, by definition, always lower than that of the reference analysis. Even in the best case, it can in the maximum be equal to the latter. The guidelines in ISO 9622 (ISO, 1999), IDF 141C:2000 (IDF, 2000), recommendation 1:13 (ADR (2002), and ICAR (2010) describe recommendations for the accuracy of the reference analysis. (The accuracy is tested regularly in an interlaboratory comparison.)

Different evaluation criteria, such as RPD, SEP, and $R E S_{\leq R}$, resulted in varying conclusions regarding the achieved accuracy. High RPD values when predicting fat content in milk are, to some extent, explained by the large range and standard deviation of fat in milk samples in the validation set. However, the large range of concentrations leads additionally to higher analytical errors in the laboratory analysis because the initial raw milk analysis calibrations for laboratory analyzers are focused on milk samples with fat ranges of 2.5 to $6 \%$ [IDF 141C:2000 (IDF, 2000), ISO 9622 (ISO, 1999)].

Near-infrared analytical devices are, in general, designed for on-farm purposes; thus, they are more robust and applicable under rougher conditions than are laboratory devices. Although analytical accuracies of most of the different milk contents were insufficient with regard to laboratory accuracy recommendations of IDF 141C:2000 (IDF, 2000), ISO 9622 (ISO, 1999), ICAR (2010), and ADR (2002), they would be acceptable if achieved under at-line or in-line measuring conditions. A lower accuracy in such measuring conditions is tolerated as long as no bias or only slight bias exists (ICAR, 2010). This is because of the more frequent data sampling compared with DHI analysis. Because of the higher frequency of sampling with the in-line measuring setup in the current study, the comparison with the recommendations for $R$ for in-line analysis was reasonable (ICAR, 2010). In this case, $2 \times$ SEP of fat, protein, lactose, and urea predictions were considerably lower than the in-line $\mathrm{R}$ recommendations, which led to $\mathrm{RES}_{<\mathrm{R}}$ of more than $95 \%$ for the prediction of these 4 milk constituents (Table 2). Referring to these recommendations, excellent prediction results were achieved for all 4 milk contents. Similar results for $\mathrm{RES}_{\leq \mathrm{R}}$ were found for most of the milk constituents investigated when recommendations for at-line analytical devices were applied (Table 2).

\section{Comparison with Other Scientific Studies}

The analysis of raw milk with NIRS was examined in several studies but using different measuring configurations, wavelength ranges, and sample preparations. Several evaluation criteria, such as the standard deviation of the validation set, SEP, and bias of prediction, as well as an independent validation set, were minimum requirements for the selection of comparable studies. Seven studies are comparable in principle and are shown in Table 4 (Purnomoadi et al., 1999; Tsenkova et al., 2001a,b, 2006; Kawasaki et al., 2008; Saranwong and Kawano, 2008; Aernouts et al., 2011).

The studies in Table 4 differed mainly in the following factors:

- Measuring mode: Almost all investigations cited in Table 4 were done in either transmission or transflection mode, which is in contrast to the present study. However, because of the requirement of small pathlengths in the transmission mode, implementation of a suitable "in-line" measuring geometry in a milking system is rather difficult from a procedural point of view.

- Measuring setup: Except for the study by Kawasaki et al. (2008), all investigations were done in a static measurement setup under laboratory conditions, with a time delay between milk sampling and spectral analysis.

- Range of milk constituents: Subsamples of milkings have a wider range of milk constituents than do milk samples from complete milkings. Ranges in fat content in the test sets of Tsenkova et al. (2001b) and Kawasaki et al. (2008) were comparable with the range in fat content in the present study. In contrast, a small range in fat content in the test set was used in the study by Saranwong and Kawano (2008), and a small range in urea content was used in the study by Kawasaki et al. (2008).

- Validation set: The number of samples in the validation set was comparatively small in all the cited studies, which could have influenced the robust- 
Table 4. Performance of model validation in different studies in literature ${ }^{1}$

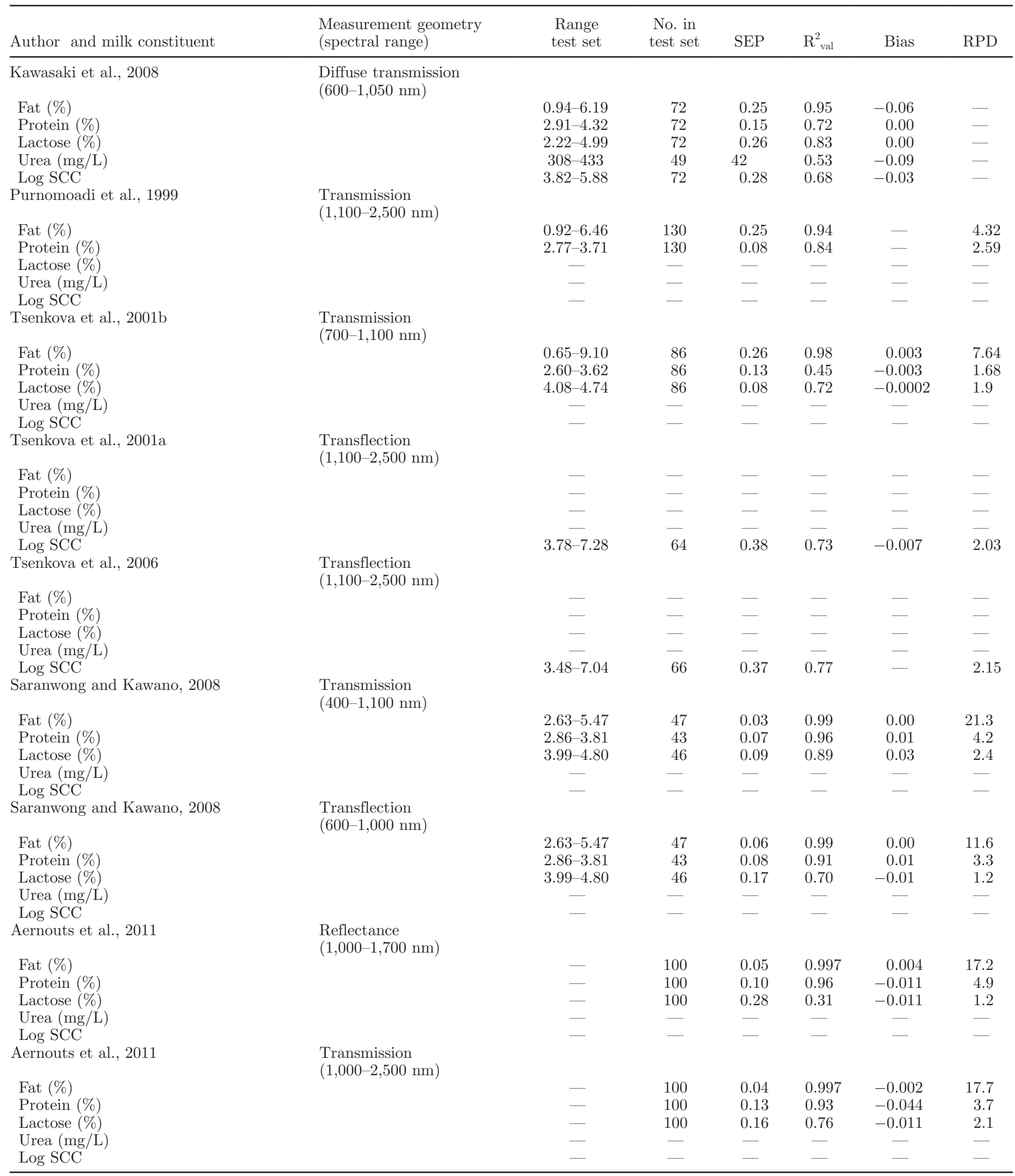

${ }^{1}$ If necessary, values were rounded, units were modified, and missing values were calculated by data from the author if possible; otherwise, they were left blank. $\mathrm{SEP}=$ standard error of prediction; $\mathrm{R}_{\text {val }}^{2}=$ coefficient of determination of validation; $\mathrm{RPD}=$ ratio of standard deviation of the validation set to SEP. 
ness of the model if they were additionally based on a small number of cows from which the samples originated. Other possible influences on the performance of NIR calibrations are wavelength range, sample presentation, and measurement geometry (Tsenkova et al., 2001b; Saranwong and Kawano, 2008; Aernouts et al., 2011), as well as differences in substrate temperature, sample set size, and data pretreatment (Williams and Norris, 2001; Blanco and Valdes, 2004; Dan et al., 2010). Williams and Norris (2001) described more than 30 different sources of errors in NIR technology, of which the ones mentioned above are the most important.

The results showed that not all milk constituents were predicted with the same accuracy. Likewise, values for $\mathrm{RPD}, \mathrm{SEP}$, and $\mathrm{R}_{\text {val }}^{2}$ in the literature sources examined varied considerably, depending on the predicted milk constituent (Table 4):

- Fat (\%): Calibrations ranging from suitable to excellent, according to their RPD values, were achieved in all the studies cited with regard to the prediction of milk fat content. Comparatively high RPD values were also achieved in the current study, basically because of a low SEP in combination with a high range and standard deviation of fat content in the milk subsamples analyzed. For example, SEP was rather small and RPD was rather high in comparison with those in the studies by Purnomoadi et al. (1999), Tsenkova et al. (2001b), and Kawasaki et al. (2008), whereas SEP values were lower in the studies by Saranwong and Kawano (2008) and Aernouts et al. (2011). Only the transmission setup used by Saranwong and Kawano (2008) achieved a higher accuracy when limits for $2 \times$ SEP were applied, according to recommendations for $R$ for laboratory purposes (Table 2).

- Protein (\%): The RPD in the current study was excellent with regard to results of most of the cited studies. Calibrations that are, according to their RPD, likewise suitable for rough screening in most NIR applications in agricultural products (Williams, 2001) were developed in the studies by Purnomoadi et al. (1999), Saranwong and Kawano (2008), and Aernouts et al. (2011). However, the cited studies measured either in the transmission or reflectance mode, which, in general, is less suitable for in-line use in milking lines.

- Lactose (\%): The RPD was considerably higher and the SEP was smaller compared with those reported in the studies listed in Table 4. Rather poor results were achieved in most studies when recommended values for $R$, for at-line or in-line devices, were compared with the $2 \times$ SEP of these studies. Considerably better results were achieved when comparing $2 \times \mathrm{SEP}$ with recommendations of $R$ in the current study compared with all the studies listed in Table 4 with regard to lactose prediction.

- Urea $(\mathrm{mg} / \mathrm{L})$ : The determination of urea content in raw milk in the current study resulted in an SEP that allowed rough screening of milk samples with regard to this milk constituent. Determination of the urea in milk with NIR was realized in only one of the cited studies (Kawasaki et al., 2008). However, SEP was too large in the cited study, especially with regard to the small range of urea contents in milk.

- Log SCC: Logarithmically transformed SCC were predicted in the studies by Tsenkova et al. (2001a), Tsenkova et al. (2006), and Kawasaki et al. (2008). Regarding SEP, analyzing results for $\log$ SCC showed considerably better results in the current study. This was also confirmed by comparison of the RPD values.

Data on the potential and accuracy of NIRS in diffuse reflection mode used in milking lines are still rare in the literature. The low SEP and high RPD values that were achieved for the NIR calibrations in this study underline the suitability of the self-designed inline analytical device. However, these results are based on 1 farm only. Further investigations need to focus on the transferability of the calibrations to other farms and on other external influences, such as feeding, cow breed, and milking parlors.

\section{CONCLUSIONS}

An in-line analytical device based on NIR diffuse reflectance measurement was developed and implemented in a milking parlor. The contents of 5 main milk constituents were predicted in raw milk samples with chemometric calibration tools. The comparison with comparative studies and with recommendations for precision and accuracy of analysis in laboratory, at-line, and in-line devices, as well as the SCC classification, led to the following conclusion. The prediction accuracy was excellent with regard to RPD values for fat and protein contents in milk. Protein, lactose, and urea contents and SCC were predicted with a low SEP. It is clear that NIR analysis of raw milk constituents will not achieve the accuracy of recommendations required in the laboratory. Nevertheless, the prediction accuracy for the milk constituents protein, lactose, and 
urea was good with regard to the reproducibility recommendations for in-line and at-line analytical devices. Near-infrared analyses with at-line and in-line instruments can, in general, be done at a higher frequency than in the laboratory. Compared with studies in the literature, improved prediction results were achieved for most of the milk contents analyzed. Overall, the analytical device was suitable for predicting the main milk constituents with a very high accuracy.

\section{ACKNOWLEDGMENTS}

This project was co-financed by the European Regional Development Fund (ERDF) in the framework of the "Zukunfsprogramm Wirtschaft Schleswig-Holstein." We gratefully acknowledge the "Zukunfsprogramm Wirtschaft Schleswig-Holstein," Polytec GmbH (Waldbronn, Germany), and SensoLogic GmbH (Norderstedt, Germany) for financial and technical support. Furthermore, we thank the Chamber of Agriculture SchleswigHolstein (Rendsburg, Germany) for enabling sampling and the Institute for Animal Breeding and Husbandry, University Kiel, for technical support.

\section{REFERENCES}

ADR (Arbeitsgemeinschaft Deutscher Rinderzüchter). 2002. ADREmpfehlung 1.13: Referenzmethode zur Bestimmung des Harnstoffgehaltes in Milch, Kontinuierliche Durchflussanalyse [ADR Recommendation 1:13 reference method for determination of urea content in milk, continuous flow analysis]. Arbeitsgemeinschaft Deutscher Rinderzüchter, Bonn, Germany.

Aernouts, B., E. Polshin, J. Lammertyn, and W. Saeys. 2011. Visible and near-infrared spectroscopic analysis of raw milk for cow health monitoring: Reflectance or transmittance? J. Dairy Sci. 94:5315-5329.

Blanco, M., and D. Valdes. 2004. Influence of temperature on the predictive ability of near infrared spectroscopy models. J. Near Infrared Spectrosc. 12:121-126.

Bruckmaier, R. M., C. E. Ontsouka, and J. W. Blum. 2004. Fractionized milk composition in dairy cows with subclinical mastitis. Vet. Med. (Praha) 49:283-290.

Chen, J. Y., C. Iyo, F. Terada, and S. Kawano. 2002. Effect of multiplicative scatter correction on wavelength selection for near infrared calibration to determine fat content in raw milk. J. Near Infrared Spectrosc. 10:301-307.

Dan, P., D. Kaina, L. Xia, and K. Xu. 2010. Multidimensional calibration of near infrared spectra for component concentration measurement in milk at different temperatures. Pages 1-4 in 2010 4th Int. Conf. Bioinform. Biomed. Eng. (iCBBE). IEEE Press, Piscataway, NJ.

Detilleux, J., J. Arendt, F. Lomba, and P. Leroy. 1999. Methods for estimating areas under receiver-operating characteristic curves: Illustration with somatic-cell scores in subclinical intramammary infections. Prev. Vet. Med. 41:75-88.

DVG (Deutsche Veterinärmedizinische Gesellschaft). 1994. Leitlinien zur Bekämpfung der Mastitis des Rindes als Herdenproblem. Vol. 3. Auflage [Guidelines for the control of bovine mastitis as a herd problem]. 3rd ed. Deutsche Veterinärmedizinische Gesellschaft, Giessen, Germany.

DVG (Deutsche Veterinärmedizinische Gesellschaft). 2002. Leitlinien zur Bekämpfung der Mastitis des Rindes als Bestandsproblem. Pages 3-29 in Sachverständigenausschuss "Subklinische Mastitis"
[Guidelines for the control of bovine mastitis as a stock problem. In the Committee of Experts on "Subclinical Mastitis."]. Deutsche Veterinärmedizinische Gesellschaft, Hannover, Germany.

Friggens, N. C., C. Ridder, and P. Lovendahl. 2007. On the use of milk composition measures to predict the energy balance of dairy cows. J. Dairy Sci. 90:5453-5467.

Harmon, R. J. 1994. Physiology of mastitis and factors affecting somatic cell counts. J. Dairy Sci. 77:2103-2112.

Heuer, C., H. J. Luinge, E. T. G. Lutz, Y. H. Schukken, J. H. van der Maas, H. Wilmink, and J. P. T. M. Noordhuizen. 2001a. Determination of acetone in cow milk by Fourier transform infrared spectroscopy for the detection of subclinical ketosis. J. Dairy Sci. $84: 575-582$.

Heuer, C., Y. H. Schukken, and P. Dobbelaar. 1999. Postpartum body condition score and results from the first test day milk as predictors of disease, fertility, yield, and culling in commercial dairy herds. J. Dairy Sci. 82:295-304.

Heuer, C., W. M. Van Straalen, Y. H. Schukken, A. Dirkzwager, and J. P. T. M. Noordhuizen. 2001b. Prediction of energy balance in high yielding dairy cows with test-day information. J. Dairy Sci. 84:471-481.

Hillerton, J. E. 1999. Redefining mastitis based on somatic cell count. Pages 4-6 in Int. Dairy Fed. (IDF) Bull. No. 345. Int. Dairy Fed., Brussels, Belgium.

Huppertz, T., A. L. Kelly, P. F. Fox, and P. L. H. McSweeney. 2006. Physical chemistry of milk fat globules. Pages 173-212 in Advanced Dairy Chemistry. Vol. 2: Lipids. Springer, New York, NY.

ICAR (International Committee for Animal Recording). 2010. Section 13-Guidelines for on-line milk analysis. Pages 325-351 in International Agreement of Recording Practices - Guidelines Approved by the General Assembly Held in Riga, Latvia, on June 2010. ICAR Sub-Comm. Milk Analysis, Int. Comm. Anim. Rec., Rome, Italy.

IDF (International Dairy Federation). 1967. Definition of mastitis. In Ann. Bull. Part III. Int. Dairy Fed., Brussels, Belgium.

IDF (International Dairy Federation). 1987. Bovine mastitis-Definition and guidelines for diagnosis. In IDF Doc. Bull. 211. Int. Dairy Fed., Brussels, Belgium.

IDF (International Dairy Federation). 2000. Standard 141C: Whole milk-Determination of milkfat, protein and lactose contentGuidance on the operation of mid-infrared instruments. Int. Dairy Fed., Brussels, Belgium.

ISO (International Organization for Standardization). 1994. ISO 57251: Accuracy (trueness and precision) of measurement methods and results - Part 1: General principles and definitions. Vol. 5725-1. Int. Organ. Stand., Geneva, Switzerland.

ISO (International Organization for Standardization). 1999. ISO 9622: Whole milk-Determination of milkfat, protein and lactose content-Guidance on the operation of mid-infrared instruments. Int. Organ. Stand., Geneva, Switzerland.

Jääskeläinen, A. J., K. E. Peiponen, and J. A. Räty. 2001. On reflectometric measurement of a refractive index of milk. J. Dairy Sci. 84:38-43.

Kamphuis, C., R. Sherlock, J. Jago, G. Mein, and H. Hogeveen. 2008. Automatic detection of clinical mastitis is improved by in-line monitoring of somatic cell count. J. Dairy Sci. 91:4560-4570.

Kawasaki, M., S. Kawamura, M. Tsukahara, S. Morita, M. Komiva, and M. Natsuga. 2008. Near-infrared spectroscopic sensing system for on-line milk quality assessment in a milking robot. Comput. Electron. Agric. 63:22-27.

Maltz, E., A. Antler, I. Halachmi, and Z. Schmilovitch. 2009. Precision concentrate rationing to the dairy cow using on-line daily milk composition sensor, milk yield and body weight. Pages 17-23 in Precision Livestock Farming '09. Wageningen Academic Publishers, Wageningen, the Netherlands.

McParland, S., G. Banos, E. Wall, M. P. Coffey, H. Soyeurt, R. F. Veerkamp, and D. P. Berry. 2011. The use of mid-infrared spectrometry to predict body energy status of Holstein cows. J. Dairy Sci. 94:3651-3661.

Melfsen, A., E. Hartung, and A. Haeussermann. 2012. Accuracy of milk composition analysis with near infrared spectroscopy in diffuse reflectance mode. Biosystems Eng. 112:210-217. 
NMC (National Mastitis Council). 2001. Guidelines on Normal and Abnormal Raw Milk Based on SCC and Signs of Clinical Mastitis. Natl. Mastitis Counc., Madison, WI.

Purnomoadi, A., K. K. Batajoo, K. Ueda, and F. Terada. 1999. Influence of feed source on determination of fat and protein in milk by near-infrared spectroscopy. Int. Dairy J. 9:447-452.

Saranwong, S., and S. Kawano. 2008. System design for non-destructive near infrared analyses of chemical components and total aerobic bacteria count of raw milk. J. Near Infrared Spectrosc. 16:389-398.

Schalm, O. W., and D. O. Noorlander. 1957. Experiments and observations leading to development of the California mastitis test. J. Am. Vet. Med. Assoc. 130:199-204.

Schmilovitch, Z., I. Shmulevich, A. Notea, and E. Maltz. 2000. Near infrared spectrometry of milk in its heterogeneous state. Comput. Electron. Agric. 29:195-207.

Schukken, Y. H., D. J. Wilson, F. Welcome, L. Garrison-Tikofsky, and R. N. Gonzalez. 2003. Monitoring udder health and milk quality using somatic cell counts. Vet. Res. 34:579-596.

SvennerstenSjaunja, K., L. O. Sjaunja, J. Bertilsson, and H. Wiktorsson. 1997. Use of regular milking records versus daily records for nutrition and other kinds of management. Livest. Prod. Sci. 48:167-174.

Toni, F., L. Vincenti, L. Grigoletto, A. Ricci, and Y. H. Schukken. 2011. Early lactation ratio of fat and protein percentage in milk is associated with health, milk production, and survival. J. Dairy Sci. 94:1772-1783.

Töpel, A. 2004. Chemie und Physik der Milch: Naturstoff- RohstoffLebensmittel. Behr, Hamburg, Germany.
Tsenkova, R., S. Atanassova, S. Kawano, and K. Toyoda. 2001a. Somatic cell count determination in cow's milk by near-infrared spectroscopy: A new diagnostic tool. J. Anim. Sci. 79:2550-2557.

Tsenkova, R., S. Atanassova, H. Morita, K. Ikuta, K. Toyoda, I. K. Iordanova, and E. Hakogi. 2006. Near infrared spectra of cows milk for milk quality evaluation: Disease diagnosis and pathogen identification. J. Near Infrared Spectrosc. 14:363-370.

Tsenkova, R., S. Atanassova, Y. Ozaki, K. Toyoda, and K. Itoh. 2001b. Near-infrared spectroscopy for biomonitoring: Influence of somatic cell count on cow's milk composition analysis. Int. Dairy J. $11: 779-783$.

Tsenkova, R., S. Atanassova, K. Toyoda, Y. Ozaki, K. Itoh, and T. Fearn. 1999. Near-infrared spectroscopy for dairy management: Measurement of unhomogenized milk composition. J. Dairy Sci. $82: 2344-2351$.

Tsenkova, R., H. Meilina, S. Kuroki, and D. H. Burns. 2009. Near infrared spectroscopy using short wavelengths and leave-one-cow-out cross-validation for quantification of somatic cells in milk. J. Near Infrared Spectrosc. 17:345-351.

Williams, P. C. 2001. Implementation of near-infrared technology Pages 145-170 in Near-Infrared Technology in the Agricultural and Food Industries. P. Williams and K. H. Norris, ed. Am. Assoc. Cereal Chem., St. Paul, MN.

Williams, P. C., and K. Norris. 2001. Variables affecting near-infrared spectroscopic analysis. Pages 171-185 in Near-Infrared Technology in the Agricultural and Food Industries. P. Williams and K. H. Norris, ed. Am. Assoc. Cereal Chem., St. Paul, MN. 